九州大学学術情報リポジトリ

Kyushu University Institutional Repository

\title{
MR Damper Modeling using Gaussian and Generalized Bell of ANFIS Algorithm
}

Choirunisa, Ikhtiar

Mechanical Engineering Department, Universitas Sebelas Maret

Ubaidi l lah

Mechanical Engineering Department, Universitas Sebelas Maret

Imaduddin, Fitrian

Mechanical Engineering Department, Universitas Sebelas Maret

Elliza Tri Maharani

Mechanical Engineering Department, Universitas Sebelas Maret

他

https://doi.org/10.5109/4491844

出版情報：Evergreen. 8 (3)，pp.673-685，2021-09. 九州大学グリーンテクノロジー研究教育センター バージョン：

権利関係 : 


\title{
MR Damper Modeling using Gaussian and Generalized Bell of ANFIS Algorithm
}

\author{
Ikhtiar Choirunisa $^{1}$, Ubaidillah ${ }^{1, *}$, Fitrian Imaduddin ${ }^{1}$, Elliza Tri Maharani ${ }^{1}$, Gigih \\ Priyandoko ${ }^{2, *}$, Saiful Amri Mazlan ${ }^{3}$ \\ ${ }^{1}$ Mechanical Engineering Department, Universitas Sebelas Maret, Jalan Ir. Sutami 36A, Kentingan, Surakarta
} 57126, Indonesia

${ }^{2}$ Electrical Engineering, Universitas Widyagama Malang, Malang, Indonesia

${ }^{3}$ Malaysia Japan International Institute of Technology, Universiti Teknologi Malaysia, Malaysia

*Author to whom correspondence should be addressed:

E-mail: ubaidillah_ft@staff.uns.ac.id, gigih@widyagama.ac.id

(Received January 7, 2021; Revised September 6, 2021; accepted September 6, 2021).

\begin{abstract}
The MR damper is well-known for its hysteresis characteristic, which needs to be modeled accurately to describe the MR damper's original state. Modeling with conventional calculations is considered less effective for MR damper because it has a very high nonlinearity. One of the modeling methods chosen is Adaptive Neuro-Fuzzy Inference System (ANFIS), using two types of membership functions: Gaussian and Generalized Bell. Overall, the results showed that Gaussian had an accuracy about 1\% higher than Generalized Bell. It can be considered in future studies to model the MR damper and designing a control system.
\end{abstract}

Keywords: MR Damper; Gaussian; Generalized Bell; ANFIS; Modeling

\section{Introduction}

The suspension system is useful for maintaining contact between the wheels and the road, and maintaining driving stability, so the vehicle remains under control ${ }^{1)}$. In a vehicle suspension system, one of them is called a semiactive device. A critical part of the semi-active device is a magnetorheological damper (MR damper) that changes the damping coefficient. MR dampers are used in industry or control structures such as in semi-active controls utilizing LQR controllers ${ }^{2)}$, industrial shock absorbers ${ }^{3)}$, and structural control ${ }^{4}$ ). The MR damper has a difference from a standard damper that generally uses a fluid such as a hydraulic fluid because it is designed using a special fluid called magnetorheological fluids (MRFs). It has been classified as one of the smart materials since it is easy to control under external influence.

MRFs are magnetic suspensions that can change their rheological properties when subjected to the magnetic field induction ${ }^{5}$. It consists of three main parts ${ }^{6)}$, namely soft magnetic particles $\left(\mathrm{Fe}_{3} \mathrm{O} 4, \mathrm{Fe}_{3}, \mathrm{Fe}\right.$, or $\mathrm{Co}$ ), carrier fluid or a soft magnetic particle suspension medium (synthetic oil or water and mineral oil), and the last is additives (a dispersant or an anti-sedimentation agent). MRFs are used in various mechanical system devices such as dampers, brakes, clutches, hydraulic valves, polishing devices ${ }^{7)}$, or semi-active vibration isolation ${ }^{8}$. This fluid is referred to as a Non-Newtonian fluid when the magnetic field is applied. After the magnetic field is removed, MRFs will be a Newtonian fluid ${ }^{9}$. MRFs act as a nonlinear component in the MR damper, which causes the MR damper to have distinctive and well-known behavior, which is hysteresis characteristic ${ }^{10}$. It needs to be modeled precisely and effectively to describe the typical behavior of MR damper ${ }^{11}$.

Many modeling techniques have been used to model the MR damper, such as dynamic modeling ${ }^{12}$. For example, a new phenomenological model based on the Bouc-Wen modeling proposed by Spencer et al. ${ }^{13)}$ in 1997. The results showed that the modeling was effective in controlling algorithm development and system evaluation. In 2005, Rene et al. ${ }^{14)}$ utilized a new mathematical model, namely the modified Lugre friction, to model the MR damper's dynamic behavior. The experimental data showed a fair degree of accuracy between the predicted and measured forces, although there were some minor differences at the low velocities. After two years in 2007, Kwok et al. ${ }^{15)}$ used the non-symmetric Bouc-Wen method identified by the Genetic Algorithm (GA) to consider the effects of the non-symmetric hysteresis behavior of MR damper, which was not considered in the original BoucWen model. In 2011, Boada et al. ${ }^{16)}$ used the Recursive Lazy Learning method based on the Neural Network to model MR damper's behavior. This method reduced the previous compilation and used the sample input to guide making a decision. Arias et al. ${ }^{17)}$ modeled the MR damper 
using a second-order polynomial model, and the results were used to design and apply a semi-active control algorithm. Dimock et al. ${ }^{18)}$ utilized Bingham's biplastic analysis to calculate shear thing and shear thickening MRF properties. Soltane et al. ${ }^{19)}$ proposed an adaptation of the accurately regulated Bingham model to reproduce the hysterical behavior of MR damper. Paul et al. ${ }^{20)}$ utilized a Neural Network model ${ }^{21)}$ consisting of 6 input neurons, 1 output neuron, and 12 neurons in a hidden layer to imitate the dynamic behavior of MR damper. Maharani et al. ${ }^{22)}$ and Han et al. ${ }^{23)}$ conducted experimental studies and mathematical modeling on MR damper.

However, these modeling methods are still inaccurately to model the hysteresis behavior of the MR damper. It is because of the high nonlinearity between the input and the output. Some modelings with conventional mathematical method are not suitable to describe the nonlinear state of the system. Because apart from being complex, the parameters are not known certainly. Complex systems require effective modeling and have a higher degree of accuracy. For this reason, the soft input technique is one of the main alternative options because it has been shown to be effective in dealing with complex problems and nonlinear behavior of control systems ${ }^{24}$. Adaptive NeuroFuzzy Inference System (ANFIS) as machine learning ${ }^{25,26)}$ was chosen as alternative modeling. ANFIS is based on artificial intelligence, which combines fuzzy systems and neural networks ${ }^{27,28)}$ using hybrid learning ${ }^{24)}$. This method is proven to generate better results of modeling. ANFIS is used in modeling MR damper or in control structures by Nugroho et al. ${ }^{10)}$, Imaduddin et al. ${ }^{29)}$, Zeinali et al. ${ }^{30)}$, Zong et al. ${ }^{31)}$, Wang ${ }^{32)}$, and Nguyen et al. 33).

The efficiency and computaional cost of ANFIS is strongly influenced by the form of membership function and the number of membership function, so this study needs to be carried out. This study was expected to develop an accurate MR damper modeling using ANFIS with Gaussian and Generalized Bell membership function to describe the MR damper's hysteresis characteristics. So, the modeling results can be considered for designing a control system in the next future studies.

\section{Research Methodology}

The MR Damper prototype was manufactured at PT Kayaba Indonesia and was designed with an annularradial-annular valve type. Furthermore, dynamic testing was carried out to measure this prototype's characterization using Shimadzu Selvopulser L-type Loading Frame with a 4830 controller. This machine works by regulating the electric current. It will calculate the damping force after getting the command to run from the exsiting program from the selvopulser (parameter values for the test are inputted in this program). After running the program, the damping force will be detected by the load cell sensor and then the value will be automatically recorded and displayed in the selvopulser program on the computer. The experimental configuration can be seen in Figure 1. Its parameters were given at different amplitude variations of 4, 8, 10, 12, and $16 \mathrm{~mm}$. Each amplitude was given a current of 0.25 A difference, starting from 0 to $0.75 \mathrm{~A}$ and a frequency of $1.5 \mathrm{~Hz}$.

\subsection{Fuzzy Inference System}

FIS (Fuzzy Inference System) is also known as a fuzzy rule based on a system composed of five function blocks 34), namely:

1. A function block that contains several fuzzy if-then rules is called a rule base.

2. A function block that defines the membership function of a fuzzy set is called a database.

3. A function block that shows the inference operation in the rule is called a decision making unit.

4. The function block that converts the cryptic input into a degree of match with a linguistic value is called the fuzzification interface block.

5. The function block that converts the fuzzy output into cryptic input is called the defuzzification interface.

The basis of the FIS system is to use the expression of the if-then logic to generate an output from a set of inputs that have been provided or desired. If-then logic is expressed in the "IF A THEN B" such as "if pressure is large, so volume is small" ${ }^{34)}$. The value of the fuzzy ifthen rule depends on the selected number of membership function configurations from the system.

In the case of MR damper, the input data for modeling is current, displacement, and velocity. There are represented by variables I, d, and v. So, the if-then logic rule is written as Equation (1),

\section{IF (I is A1) AND (d is B1) AND ( $v$ is C1)}

\section{THEN}

$$
f 1=p 1 I+q 1 d+r 1 v+s 1
$$

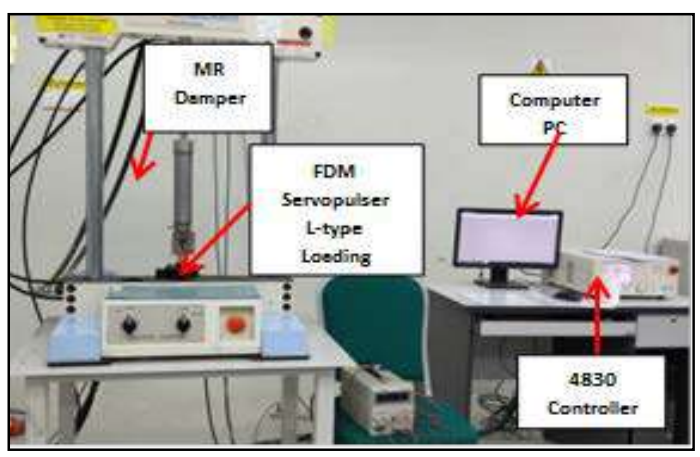

Fig. 1: Experimental set up

\subsection{ANFIS Algorithm}

ANFIS (Adaptive Neuro-Fuzzy Inference System) is a modeling technique that is composed of a multilayer network structure and utilizes fuzzy reasoning and neural 
network learning ${ }^{35)}$, so the output of a fuzzy system with an exact value will be generated from a fuzzy input model of cryptic value ${ }^{36}$ ). In ANFIS there is a hybrid learning algorithm ${ }^{35)}$ that is applied to update the parameters so that the final parameters used in the fuzzy system will be obtained. Two other methods, namely gradient descent method and least squares method ${ }^{35}$ ) were utilized to adjust the premise parameter and the consequent parameter identifier, respectively. ANFIS is a multilayer network where each layer has calculations to solve the problems borne by each layer, as written here ${ }^{36)}$ :

1. The first layer is for calculating the fuzzy membership of the input data.

2. The second layer is to calculate the fitness of each fuzzy rule.

3. The third layer is to calculate the normalized fitness.

4. The fourth layer is for calculating the output of each fuzzy rule.

5. The fifth or last layer is to calculate the total output from the fuzzy system.

Talpur et al. in $2017^{37)}$ stated that choosing the number of membership functions and the form of membership functions will affect ANFIS performance in terms of complexity and level of accuracy. The membership function is defined as a function that describes the level or degree of input data in a value range of 0 to 1 so that the difference in the quality of data can be clearly identified. The membership function is described in the form of a curve and is constructed by several parameters. In this study, the membership functions are used for MR damper modeling, which was Gaussian and Generalized Bell, as can be seen in Figures 2 and 3 .

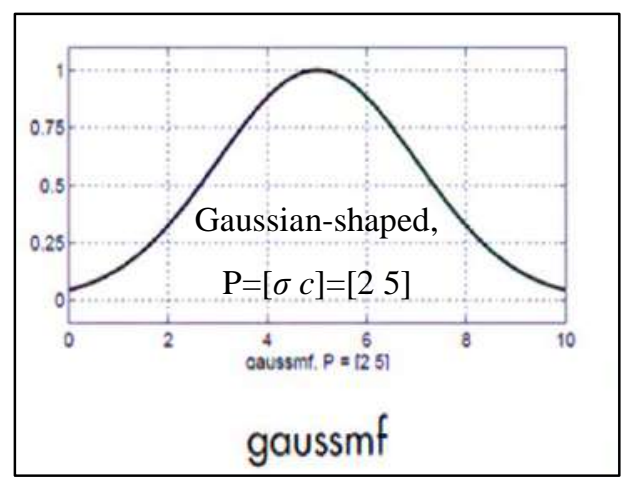

Fig. 2: Gaussian MF.

There are three inputs: current, displacement and velocity from the $20^{\text {th }}$ cycle data measurement are used to generate the value of force as output. In the first layer, the formula of Gaussian and Generalized Bell is used to generate the premise parameters, that are shown in Equation (2) and (3),

$$
\begin{aligned}
& f(I, d, v)=e^{-\frac{(x-c i)^{2}}{2 \sigma i^{2}}} \\
& f(I, d, v)=\frac{1}{1+/ \frac{x-C}{a} / 2 b}
\end{aligned}
$$

where, $f(I, d, v)$ is the output of the first layer as a function of current, displacement, or current, while $\sigma i, c i, a, b, c$ are premise parameters.

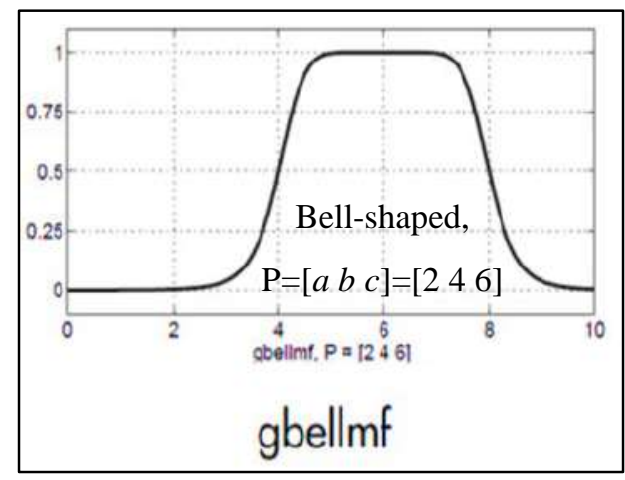

Fig. 3: Generalized Bell MF.

The calculation results from the first layer will be calculated in the second layer using AND rules that are written in Equation (4) as follows,

$$
O 2, i=w i=f i(I) \times f i(d) \times f i(v)
$$

where $f i(I)$ is the output for the current input, $f i(d)$ is the output for the displacement input, and $f i(v)$ is the output for the velocity input. Each function's magnitude is influenced by the value of the premise parameters obtained from the first layer.

The third layer's output is the average of the multiplication between each input divided by the number of nodes. The formula, as shown in Equation (5),

$$
O 3, i=\overline{w i}=w i / \sum_{i=1}^{n} w i
$$

where $\overline{w l}$ is the relative rule weight of the $i$ node.

The output from the fourth layer is calculated according to Equation (6),

$$
O 4, i=\overline{w i} g i=\overline{w i}(p i(I)+q i(d)+r i(v)+s i)
$$

where $p i, q i, r i$ and $s i$ represent the values of the consequent parameters that are obtained after the training process is complete.

In this study, however, the output from the membership function was chosen to be constant, so that $p i=q i=r i$ were assumed 0 . Then, the consequent parameters in the fourth layer are represented only by the value of $s 1$ 
$(g i=s i)$. So, the final output from the fourth layer can be written as Equation (7),

$$
\text { O4,i }=\overline{w i} g i=\overline{w i}(s i)
$$

The average output of the membership function in the fourth layer is recalculated in the fifth layer as the final output, as shown in Equation (8),

$$
\text { O5,i }=\sum_{i=1}^{n} \overline{w i} g i=\sum_{i=1}^{n} \overline{w i}(s i) / \sum_{i=1}^{n} w 1
$$

Relative error value from ANFIS is calculated using RMSE from Equation (9),

$$
R M S E=\sqrt{1 / n}\left(\sum(\bar{Z} t-Z) \wedge 2\right.
$$

where $n$ is number of testing sets, $\overline{Z t}$ is actual force, and $Z$ is predicted force.

\section{Results and Discussion}

\subsection{MR Damper Characterization}

The data from measurement of the MR damper characteristics were taken from the $16^{\text {th }}$ cycle of the entire MR damper testing cycle and generated a hysteresis relationship between force and velocity that can be seen in Figures $4-8$. The damping force will increase when the electric current tested on the MR damper is also high as a result of the increased pressure drop that occurs in the valve ${ }^{29)}$. Besides the pressure drop, another factor affecting the damping force's magnitude is the high and low amplitude value. It corresponds to the theory of simple harmonic vibrations, which is written according to Equation (10),

$$
Y=A \sin (\omega t)
$$

where $Y$ is the relative displacement, $A$ is the amplitude, $\omega$ is the natural frequency, and $t$ is the time.

From Equation (10), the amplitude will affect the relative displacement of a vibration system. The derivative of displacement as a function of time (in this case is the relative velocity of the piston rod on the MR damper) will directly affect the damping force. Since the magnitude of the damping force is calculated according to the formula $=c v, c$ is the damping force coefficient, and $v$ is the velocity.

Based on those figures, the damping force generated at amplitudes of $4 \mathrm{~mm}$ to $16 \mathrm{~mm}$ when on the on-state condition $(0.75 \mathrm{~A})$ was more significant than on the offstate condition (0 A). Also, the damping force for the overall amplitude of $16 \mathrm{~mm}$ had the most terrific value compared to the others. This was according to the theory that the damping force is influenced by the damping coefficient and the piston rod's relative velocity, which is determined by the amplitude value.

\subsection{The Results of MR Damper Modeling}

MR damper modeling was done using ANFIS with two different membership functions with the number of epochs was 2500 and the same configurations of 3-5-6 that can be seen in Figure 9. The configurations in this study were selected based on the research that was done by Imaduddin et al. ${ }^{29)}$, while the analysis was done by Zeinali et al. ${ }^{30)}$.

In ANFIS, there is a term called Root Mean Square Error (RMSE), which describes the amount of data calculation error during the training process, and the results will appear when the training process is complete. The error value of the training process for Gaussian and Generalized Bell is shown in Figures 10 and 11, respectively, with the result of Gaussian was 0.1011 while Generalized Bell was 0.1079. From the graph, it can be seen that the error value generated between the two membership functions showed the results reaching 0.1 . However, the level of accuracy of Gaussian was better than Generalized Bell because it showed an error value, which was 0.1011 and 0.1079 , respectively. The number of epochs and fuzzy-rules was the same; it turned out that the training error value had a 0.0068 difference. The graph's trend showed that the calculated error value for Generalized Bell was saturated when it reached almost 1000 to 2500 epochs. When the number of iterations increased, then the error value remained the same. In addition to the error value, the differences in ANFIS training results with Gaussian and Generalized Bell are shown in Table 1.

Furthermore, the ANFIS training process generated parameters representing all training data and are known as premise parameters and consequent parameters. The premise parameter determines the degree of membership from the training data, while the consequent parameter determines the membership function's output value. These parameters are formulated in determining the value of an output from the modeling results. Tables 2 - 4 show the premise parameters' values and consequent parameters for Gaussian and Generalized Bell membership function. Based on the tables, the number of premise parameters represents the membership function configuration's input value, namely 3-5-6. Meanwhile, the number of consequent parameters is the product of the membership function's configuration as a fuzzy if-then rule.

In the scope of MR damper modeling, one of the useful parameters that can be chosen to predict the damping force using ANFIS is velocity, as described by Zeinali et al. ${ }^{30}$. Figures $12-14$ show the force's prediction versus velocity in off-state condition at $0 \mathrm{~A}$ and on-state at $0.75 \mathrm{~A}$ with the amplitude variation for 4,10 , and $16 \mathrm{~mm}$. Based on the figures, the Gaussian and Generalized Bell membership 
functions successfully predicted the peak value of forcevelocity.

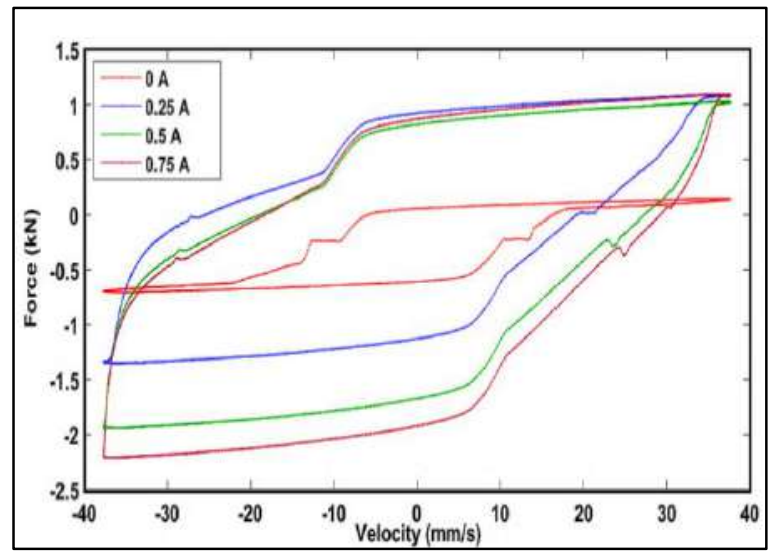

Fig. 4: Plot of force-velocity for $4 \mathrm{~mm}$

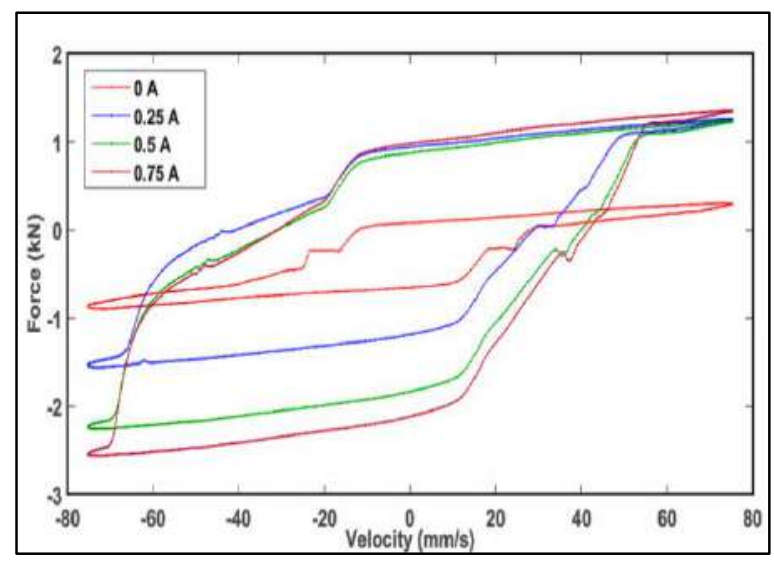

Fig. 5: Plot of force-velocity for $8 \mathrm{~mm}$

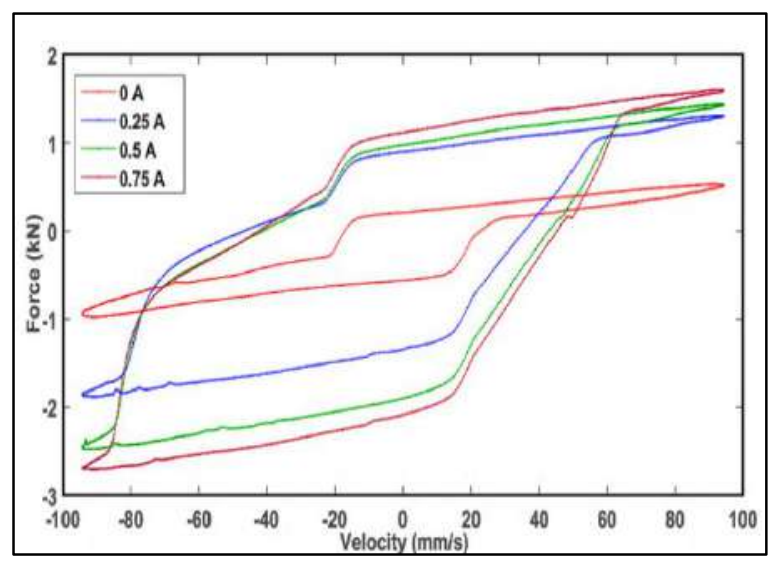

Fig. 6: Plot of force-velocity for $10 \mathrm{~mm}$

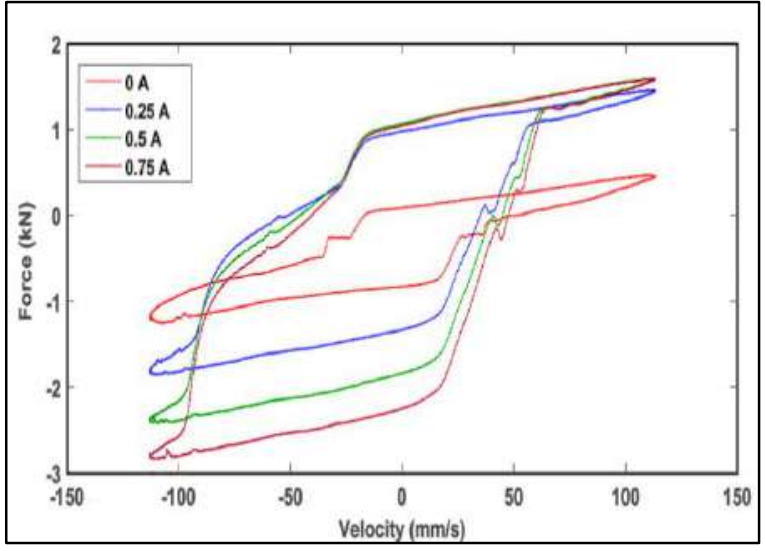

Fig. 7: Plot of force-velocity for $12 \mathrm{~mm}$

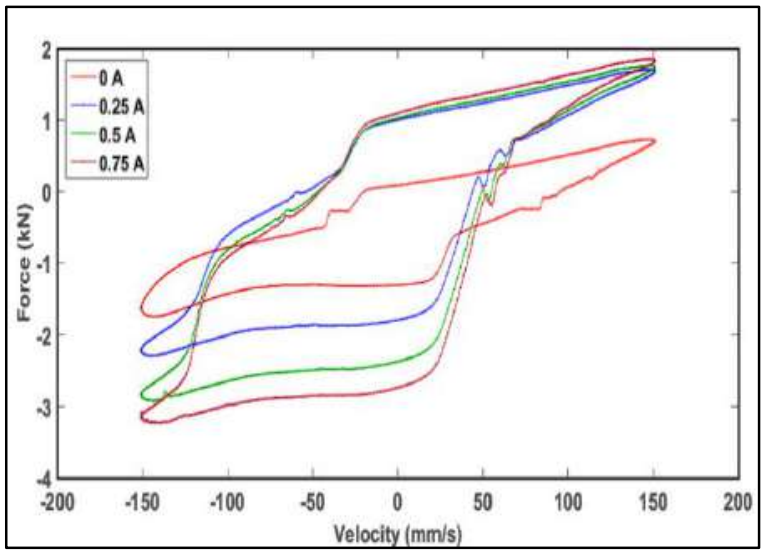

Fig. 8: Plot of force-velocity for $16 \mathrm{~mm}$

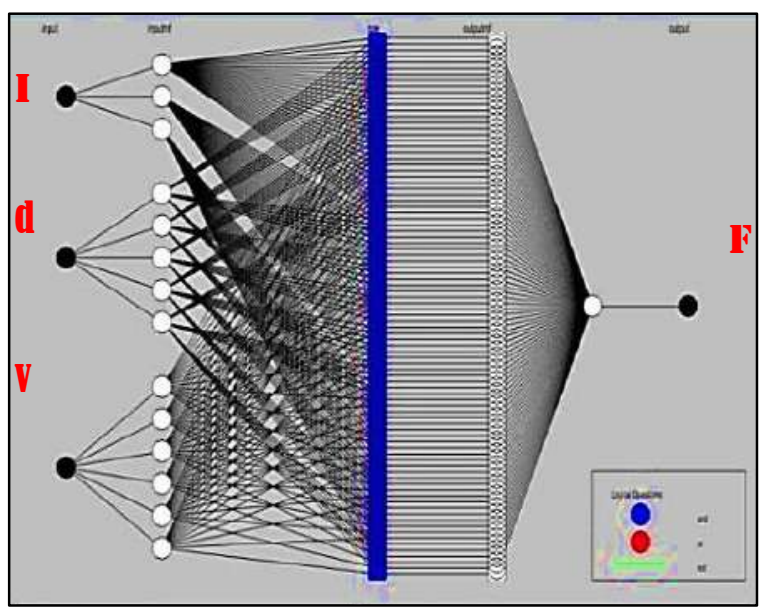

Fig. 9: ANFIS structure for 3-5-6 MF. 


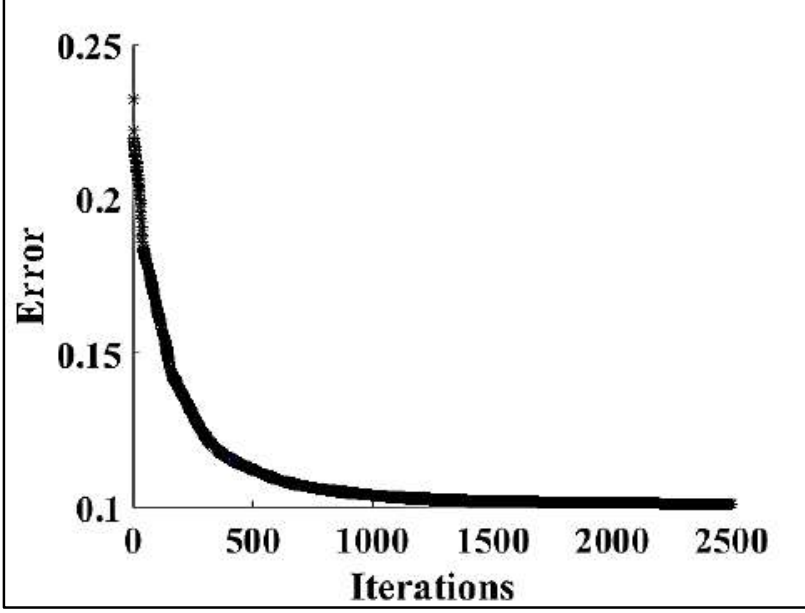

Fig. 10: Gaussian RMSE

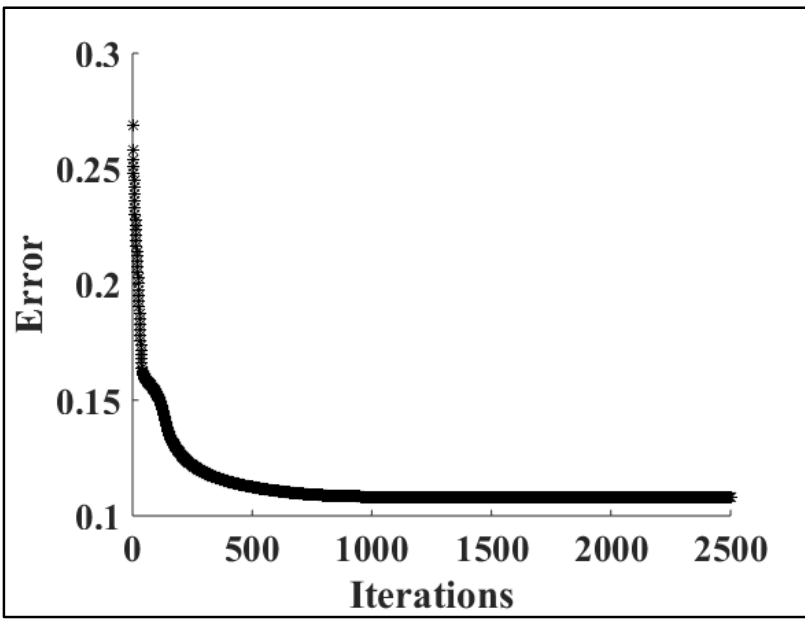

Fig. 11: Generalized Bell RMSE

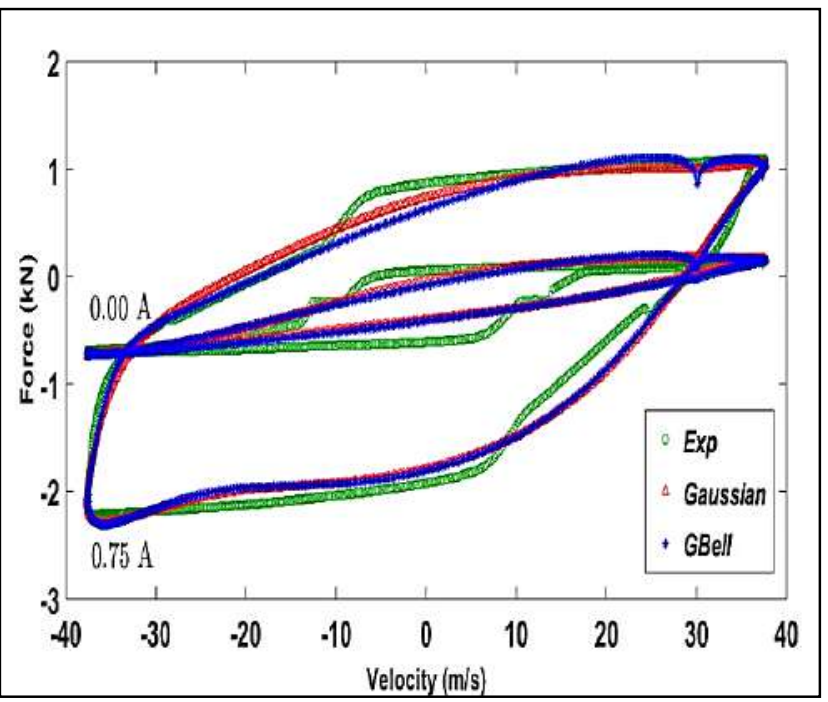

Fig. 12: MR Damper modeling results on the $16^{\text {th }}$ cycle test in off-state (0 A) and on-state for $4 \mathrm{~mm}$

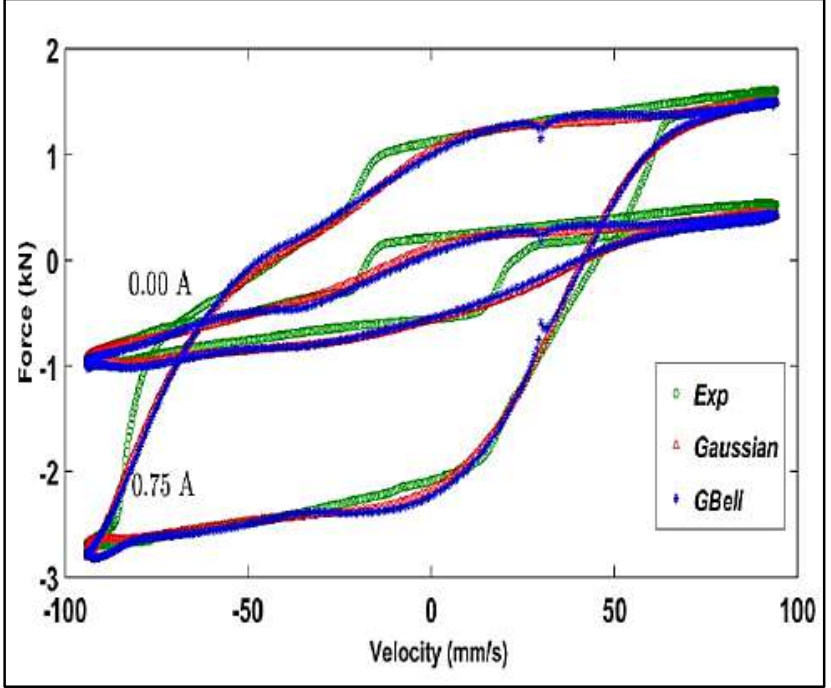

Fig. 13: MR Damper modeling results on the $16^{\text {th }}$ cycle test in off-state (0 A) and on-state for $10 \mathrm{~mm}$

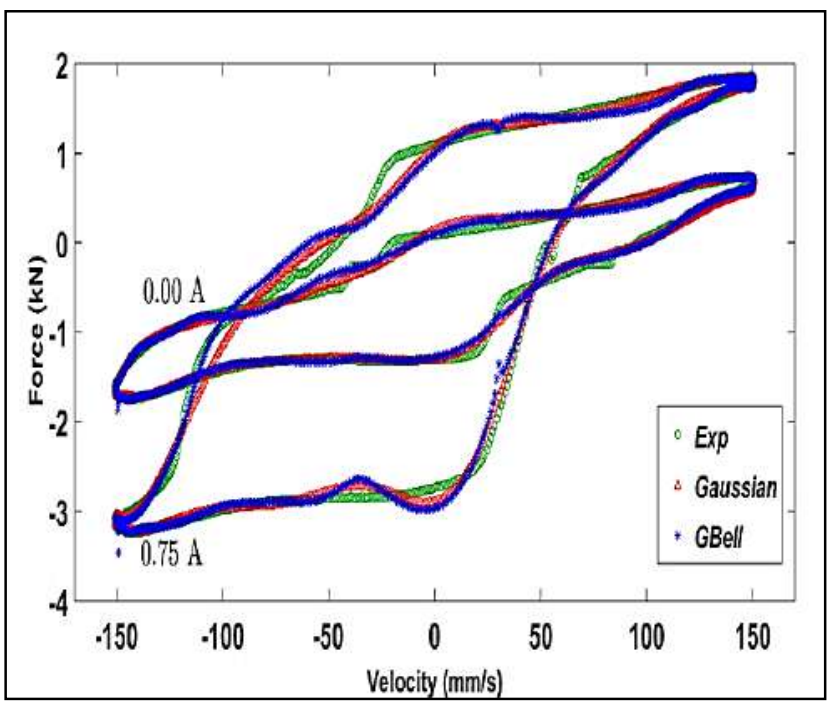

Fig. 14: MR Damper modeling results on the $16^{\text {th }}$ cycle test in off-state (0 A) and on-state for $16 \mathrm{~mm}$

Table 1 ANFIS information for Gaussian and Generalized Bell

\begin{tabular}{|l|l|l|}
\hline $\begin{array}{l}\text { ANFIS } \\
\text { Informations }\end{array}$ & Gaussian & Generalized Bell \\
\hline Epochs & 2500 & 2500 \\
\hline Number of nodes & 214 & 214 \\
\hline $\begin{array}{l}\text { Number of linear } \\
\text { parameters }\end{array}$ & 90 & 90 \\
\hline
\end{tabular}




\begin{tabular}{|l|l|l|}
\hline $\begin{array}{l}\text { Number of nonlinear } \\
\text { parameters }\end{array}$ & 28 & 42 \\
\hline $\begin{array}{l}\text { Number of fuzzy- } \\
\text { rules }\end{array}$ & 90 & 90 \\
\hline $\begin{array}{l}\text { Value of training } \\
\text { error }\end{array}$ & 0,1011 & 0,1079 \\
\hline
\end{tabular}

Table 2 Premise parameters for Gaussian MF.

\begin{tabular}{|c|c|c|c|}
\hline Input & MF. & $\boldsymbol{\sigma}$ & c \\
\hline \multirow[t]{3}{*}{ Current } & 11 & 0.039756 & -0.004153 \\
\hline & 12 & 0.604219 & -0.351618 \\
\hline & 13 & 0.320881 & 0.72403 \\
\hline \multirow[t]{5}{*}{ Displacement } & 21 & 5.098082 & $\begin{array}{l}- \\
20.57685 \\
1\end{array}$ \\
\hline & 22 & 4.499525 & -8.989566 \\
\hline & 23 & 1.36592 & -0.782151 \\
\hline & 24 & 2.643117 & 5.528595 \\
\hline & 25 & 2.119668 & 8.575908 \\
\hline \multirow[t]{6}{*}{ Velocity } & 31 & 30.193096 & $\begin{array}{l}- \\
151.0422 \\
84\end{array}$ \\
\hline & 32 & 38.732401 & -87.4658 \\
\hline & 33 & 22.121275 & $\begin{array}{l}- \\
35.60300 \\
5\end{array}$ \\
\hline & 34 & 22.4923 & 9.701959 \\
\hline & 35 & 37.153932 & 64.40899 \\
\hline & 36 & 45.287408 & $\begin{array}{l}140.3465 \\
63\end{array}$ \\
\hline
\end{tabular}

Table 3 Premise parameters for Generalized Bell MF.

\begin{tabular}{|l|c|l|l|l|}
\hline \multicolumn{1}{|c|}{ Input } & $\begin{array}{c}\text { M } \\
\text { F }\end{array}$ & \multicolumn{1}{c|}{ A } & b & c \\
\hline Current & 11 & 0.002286 & 2.00917 & $-8.66 \mathrm{E}-05$ \\
& & & 4 & \\
\hline & 12 & 0.33519 & 1.95733 & 0.197528 \\
& & & 7 & \\
\hline
\end{tabular}

\begin{tabular}{|c|c|c|c|c|}
\hline & 13 & 0.211905 & $\begin{array}{l}2.01876 \\
6\end{array}$ & 0.602006 \\
\hline \multirow[t]{5}{*}{$\begin{array}{l}\text { Dsiplacemen } \\
\text { t }\end{array}$} & 21 & 4.26646 & $\begin{array}{l}1.79238 \\
2\end{array}$ & -16.611529 \\
\hline & 22 & 4.094669 & $\begin{array}{l}3.59171 \\
8\end{array}$ & -7.706637 \\
\hline & 23 & 2.944155 & $\begin{array}{l}- \\
0.16580 \\
8\end{array}$ & 0.100385 \\
\hline & 24 & 4.848748 & $\begin{array}{l}6.88285 \\
9\end{array}$ & 6.831874 \\
\hline & 25 & 6.871987 & 3.79629 & 13.540689 \\
\hline \multirow[t]{6}{*}{ Velocity } & 31 & $\begin{array}{l}32.69824 \\
4\end{array}$ & $\begin{array}{l}1.27020 \\
5\end{array}$ & $\begin{array}{l}148.67971 \\
7\end{array}$ \\
\hline & 32 & $\begin{array}{l}33.15936 \\
4\end{array}$ & $\begin{array}{l}1.17714 \\
6\end{array}$ & -90.40958 \\
\hline & 33 & $\begin{array}{l}29.43965 \\
9\end{array}$ & 0.75816 & -35.797875 \\
\hline & 34 & $\begin{array}{l}30.15750 \\
7\end{array}$ & $\begin{array}{l}- \\
0.04668 \\
3\end{array}$ & 30.09459 \\
\hline & 35 & $\begin{array}{l}40.25923 \\
2\end{array}$ & $\begin{array}{l}1.61227 \\
6\end{array}$ & 81.067577 \\
\hline & 36 & $\begin{array}{l}30.63752 \\
8\end{array}$ & $\begin{array}{l}1.14221 \\
1\end{array}$ & $\begin{array}{l}150.46895 \\
6\end{array}$ \\
\hline
\end{tabular}

Following the theory, the damping force generated from ANFIS modeling using Gaussian and Generalized Bell was directly proportional to the increase in amplitude and electric current.

However, there was an exception for $10 \mathrm{~mm}$ because one of the velocity-damping force's peak value was not predicted correctly. It was caused by the small difference value of the displacement from 8 to $10 \mathrm{~mm}$ and 10 to 12 $\mathrm{mm}$, while the other displacement parameters had a $4 \mathrm{~mm}$ difference value, namely 4, 8, 12, and $16 \mathrm{~mm}$. Still, Gaussian and Generalized Bell membership functions were able to map the damping force, which was almost the same as the test result data. The evaluation results of the relative error values to the 16 th cycle data testing are shown in Table 5.

Furthermore, it can be determined that each membership function's level of accuracy is compared with the average relative error values in the same current 
conditions. In the off-state condition (0 A), Gaussian and Generalized Bell generated an average relative error value of $7.45 \%$ and $7.71 \%$, respectively. The same phenomenon also occurred in the on-state condition $(0.75 \mathrm{~A})$ for Gaussian and Generalized Bell, which generated an average relative error value of $12.14 \%$ and $13.20 \%$. From there, it can be observed that the average relative error values generated by Gaussian both in off-state and onstate conditions had a higher level of accuracy than Generalized Bell. A lower relative error value evidenced this fact. The same result applied to currents of 0.25 and $0.5 \mathrm{~A}$. 
MR Damper Modeling using Gaussian and Generalized Bell of ANFIS Algorithm

Table 4 Consequent parameters for Gaussian and Generalized Bell

\begin{tabular}{|c|c|c|c|c|c|}
\hline \multirow{2}{*}{$\begin{array}{l}\text { If-then } \\
\text { Rules }\end{array}$} & \multicolumn{2}{|c|}{ Consequent Parameters } & \multirow[t]{2}{*}{ If-then Rules } & \multicolumn{2}{|c|}{ Consequent Parameters } \\
\hline & Gaussian & Generalized Bell & & Gaussian & Generalized Bell \\
\hline 1 & -8.793647698 & -25.81086649 & 46 & 2.19384411 & 6.12074608 \\
\hline 2 & -2.29320457 & -0.4886648 & 47 & 0.817232405 & -0.345759205 \\
\hline 3 & -1.748439591 & -3.046028459 & 48 & 1.620747585 & 0.052241079 \\
\hline 4 & -1.673680452 & 2.935599502 & 49 & -1.353341094 & -4.125143259 \\
\hline 5 & -1.528027213 & -3.245283371 & 50 & -1.308399275 & -4.311688414 \\
\hline 6 & -2.051516492 & -3.80859061 & 51 & 0.103466957 & 0.142749218 \\
\hline 7 & -2.125132976 & -4.136189761 & 52 & 1.335350971 & 2.490750721 \\
\hline 8 & -0.716557057 & -2.459437291 & 53 & 0.857580462 & 0.767886206 \\
\hline 9 & -0.512852651 & -2.065684941 & 54 & 1.644383943 & 1.559701725 \\
\hline 10 & -0.075548291 & 4.70334813 & 55 & -1.732805111 & -3.981187687 \\
\hline 11 & -0.584024313 & -2.839468931 & 56 & -0.192948313 & 0.689588443 \\
\hline 12 & -0.161818266 & -2.498484743 & 57 & 0.682806556 & 2.483973398 \\
\hline 13 & -1.869149739 & -0.203973824 & 58 & 0.894222137 & 0.028510324 \\
\hline 14 & -0.718483185 & 1.236860981 & 59 & 1.033172705 & 1.626058501 \\
\hline 15 & -0.099990276 & 1.764036176 & 60 & 1.762638645 & 3.628203913 \\
\hline 16 & -1.664230426 & -4.256253594 & 61 & -5.362076276 & -15.0646137 \\
\hline 17 & -0.513686034 & 1.156332972 & 62 & -4.249359434 & 2.38346904 \\
\hline 18 & -0.048867155 & 1.846023437 & 63 & -2.794574442 & 1.819955267 \\
\hline 19 & -2.139455656 & -3.106856581 & 64 & -4.58750393 & -14.82540668 \\
\hline 20 & -0.031140378 & 0.721223673 & 65 & -0.717376086 & 5.827991202 \\
\hline 21 & -1.823211229 & -3.816942996 & 66 & 2.051742022 & 14.9858533 \\
\hline
\end{tabular}


EVERGREEN Joint Journal of Novel Carbon Resource Sciences \& Green Asia Strategy, Vol. 08, Issue 03, pp673-685, September 2021

\begin{tabular}{|c|c|c|c|c|c|}
\hline 22 & -0.896382293 & 1.705572623 & 67 & -3.82051117 & -1.468492107 \\
\hline 23 & -0.37054444 & -0.977036973 & 68 & -2.926865778 & -0.627888446 \\
\hline 24 & -0.060391567 & -0.793907304 & 69 & -2.626727088 & -0.207408557 \\
\hline 25 & -0.149420276 & 1.787449994 & 70 & -3.149799095 & -8.790917453 \\
\hline 26 & -1.320077109 & -4.155640305 & 71 & 1.304391259 & 6.246806869 \\
\hline 27 & -0.919095751 & -2.567454311 & 72 & 1.82939483 & 6.616388278 \\
\hline 28 & -0.242388313 & 2.245042636 & 73 & -3.646147508 & -7.061133014 \\
\hline 29 & -0.573313368 & -1.739068096 & 74 & -2.821149597 & -6.231396294 \\
\hline 30 & -0.102770496 & -0.545103018 & 75 & -3.194661334 & -5.88208006 \\
\hline 31 & -3.90276916 & -11.83591939 & 76 & 1.140568842 & 5.867730054 \\
\hline 32 & -1.733557774 & 2.237976863 & 77 & 1.231250807 & 0.398225532 \\
\hline 33 & -1.090365173 & 1.721869009 & 78 & 1.954736388 & 0.407716387 \\
\hline 34 & -2.278949931 & -10.24892461 & 79 & -3.320124696 & -6.447846344 \\
\hline 35 & 0.923475591 & 5.178862868 & 80 & -3.31725402 & -6.308970276 \\
\hline 36 & -0.545681664 & 6.880643753 & 81 & 0.290034143 & 0.673140517 \\
\hline 37 & -1.815589925 & -1.000446862 & 82 & 1.03219264 & 2.718555186 \\
\hline 38 & -0.990986112 & -0.351345334 & 83 & 1.301484217 & 1.050095046 \\
\hline 39 & -0.852168765 & 0.142502653 & 84 & 1.950669566 & 1.772475946 \\
\hline 40 & -0.722267202 & -5.323496547 & 85 & -4.73095417 & -7.801847737 \\
\hline 41 & 1.231421939 & 4.526313185 & 86 & 0.022345596 & 1.499529935 \\
\hline 42 & 1.386741155 & 4.74104485 & 87 & 0.346484995 & 2.304890225 \\
\hline 43 & -1.881660815 & -5.6554021 & 88 & 1.491668348 & 1.888206377 \\
\hline 44 & -0.798857651 & -4.342847263 & 89 & 1.310564375 & 1.056642497 \\
\hline 45 & -1.390561544 & -4.500251447 & 90 & 1.984501282 & 2.623060161 \\
\hline
\end{tabular}


Table 5 Model relative error to the $16^{\text {th }}$ cycle measurement data

\begin{tabular}{|c|c|c|c|c|c|c|c|c|}
\hline \multirow{2}{*}{ Amplitudes } & \multicolumn{3}{|c|}{ Gaussian Relative Error (\%) } & \multicolumn{2}{c|}{ Generalized Bell Relative Error (\%) } \\
\cline { 2 - 9 } & $\mathbf{0 . 0 A}$ & $\mathbf{0 . 2 5 A}$ & $\mathbf{0 . 5 0 A}$ & $\mathbf{0 . 7 5 A}$ & $\mathbf{0 . 0 A}$ & $\mathbf{0 . 2 5 A}$ & $\mathbf{0 . 5 0 A}$ & $\mathbf{0 . 7 5 A}$ \\
\hline $4 \mathrm{~mm}$ & 8.93 & 11.32 & 10.61 & 11.84 & 9.12 & 12.48 & 10.88 & 12.27 \\
\hline $8 \mathrm{~mm}$ & 6.43 & 10.30 & 11.12 & 11.52 & 7.60 & 9.86 & 13.16 & 13.05 \\
\hline $10 \mathrm{~mm}$ & 9.96 & 9.83 & 10.93 & 14.54 & 10.24 & 8.61 & 10.92 & 15.53 \\
\hline $12 \mathrm{~mm}$ & 7.32 & 8.95 & 12.13 & 13.13 & 6.72 & 10.03 & 13.70 & 14.14 \\
\hline $16 \mathrm{~mm}$ & 4.62 & 7.37 & 8.48 & 9.69 & 4.88 & 7.22 & 9.27 & 11.04 \\
\hline Averages & $\mathbf{7 . 4 5}$ & $\mathbf{9 . 5 5}$ & $\mathbf{1 0 . 6 5}$ & $\mathbf{1 2 . 1 4}$ & $\mathbf{7 . 7 1}$ & $\mathbf{9 . 6 4}$ & $\mathbf{1 1 . 5 8}$ & $\mathbf{1 3 . 2 0}$ \\
\hline
\end{tabular}

Besides the current, another parameter to determine the quality of Gaussian against Generalized Bell compared at the relative error value when the same amplitude was applied. For $4 \mathrm{~mm}$, the relative error value in Gaussian for each electric current started from $0 ; 0.25 ; 0.5$; and $0,75 \mathrm{~A}$ was 8.93 ; 11.32; 10.61; and $11.84 \%$. Consequently, Generalized Bell generated relative error values of 9.12, $12.48,10.88$; and $12.27 \%$. When the amplitude was 16 $\mathrm{mm}$, the relative error for Gaussian was 4.62; 7.37; 8.48; and 9.69\%, while Generalized Bell is 4.88; 7.22; 9.27; and $11.04 \%$ (for each current from $0-0.75 \mathrm{~A}$ ). These results prove that Gaussian had a higher level of accuracy than its counterpart (Generalized Bell). Similar results also occurred at amplitudes of 8, 10, and $12 \mathrm{~mm}$.

Besides that, Gaussian has the advantage of distinguishing data quality, for example, small or large, high or low ${ }^{37}$. A study by ${ }^{38)}$ proven that Gaussian has the best RMSE compared to others. It is because Gaussian can plot curves smoothly ${ }^{37,38)}$ and non-zero at any point ${ }^{37}$. Based on the table, the relative error values will increase when the amount of electric current also increases. For example, at an amplitude of $16 \mathrm{~mm}$, the relative error value for Gaussian in off-state condition (0 A) was 4.62\% while in on-state condition (0.75 A) was $9.69 \%$. The phenomenon also true for Generalized Bell, which generated the relative error value at $4.88 \%$ in the off-state condition and $11.04 \%$ in the on-state condition. These results were different from what has been studied by ${ }^{29}$. The study stated that the greater the value of electric current and frequency, the smaller relative error values generated, and the relative error values began to consistent above the $1 \mathrm{~Hz}$ frequency. However, it was further explained that there are no clear facts about this phenomenon. Most likely due to anomalies originating from the data test, which require the same study with the other data from different input and MR damper type ${ }^{29}$.

Overall, the relative error value generated by the two ANFIS models was under $20 \%$, and Gaussian showed an accuracy level is around 1\% higher than Generalized Bell, with the maximum relative error was about $14.54 \%$ and $15.53 \%$. These results corresponded to the value of the training error, which shows that Gaussian was smaller than Generalized Bell, so the accuracy of Gaussian was higher than Generalized Bell. It can occur due to a difference in the RMSE value generated during the training process. If the RMSE value is small, then the more accurate the calculations during modeling will be. In 2015, Gaxiola et al. ${ }^{38)}$ conducted a study to compare several types of membership functions namely Triangular, Gaussian, Trapezoidal, and Generalized Bell. These results from the study will be used to predict cases of Mackey-Glass time series. It showed that the best average prediction error (APE) was obtained by Gaussian, which was 0.0659 . In addition, Ali et al. from ${ }^{39)}$ proved that Gaussian was suitable and performs well when used in systems dealing with both probability and statistics. Although Gaussian was only formed by two parameters ( $\sigma$ and $c)^{37}$ ), but this membership function has advantage can precisely, accurately, and clearly of distinguishing data quality, for example small or large, high or low ${ }^{40}$ ). Still, study by ${ }^{37}$ proven that Gaussian has the best RMSE compared to others. It is because Gaussian is able to plot curves smoothly ${ }^{37,40)}$ and concise notation so it is able to represent data effectively and non-zero at any point ${ }^{40}$.

\section{Summary}

The MR damper was modelled using ANFIS with two membership functions, namely Gaussian and Generalized Bell. Each membership function was given the same ANFIS training parameters to generate the best results 
from one proposed model. This study indicated that the training error value of Gaussian was 0.1011, while Generalized Bell was 0.1079. These membership functions generate training error value was close to 0.1 . However, Gaussian showed an accuracy level of about $1 \%$ higher than Generalized Bell. Also, Gaussian has the best achieve than its counterparts because Gaussian can plot curves smoothly and concise notation to represent data effectively and non-zero at any point, although two parameters only form Gaussian. The evidence of its accuracy was from the maximum relative error value tested from one of the MR Damper test cycles in off-state and on-state conditions, which was $14.54 \%$ for Gaussian and $15.53 \%$ for Generalized Bell. Thus, it can be used as an MR damper modeling consideration in future studies' control system.

\section{Acknowledgements}

Authors would like to acknowledge Universitas Sebelas Maret for financial support through Hibah Grup Riset Penelitian 2021.

\section{Nomenclature}

$\begin{array}{ll}n & \text { number of testing sets }(-) \\ \overline{Z t} & \text { actual force }(\mathrm{kN}) \\ Z & \text { predicted force }(\mathrm{kN}) \\ Y & \text { relative displacement }(\mathrm{mm}) \\ A & \text { amplitude }(\mathrm{mm}) \\ \omega & \text { natural frequency }(\mathrm{Hz}) \\ t & \text { time (s) }\end{array}$

\section{References}

1) S. Ebrahimi-nejad, M. Kheybari, S. Vahid, and N. Borujerd, "Multi-objective optimization of a sports car suspension system using simpli fi ed quarter-car models," Mech. Ind. 21, 412 (2020). doi:doi.org/10.1051/meca/2020039.

2) G. Kumar, A. Kumar, and R.S. Jakka, "M echanics an adaptive lqr controller based on pso and maximum predominant frequency approach for semi-active control scheme using mr damper,” Mech. Ind. 19, 109 (2018). doi:doi.org/10.1051/meca/2018018.

3) A.M. $\tilde{A}$, and M. Hauke, "Application of magnetorheological fluid in industrial shock absorbers,” Mech. Syst. Signal Process., 28 528-541 (2012). doi:10.1016/j.ymssp.2011.11.008.

4) Z.Q. Gu, and S.O. Oyadiji, "Application of $\mathrm{mr}$ damper in structural control using anfis method," Comput. Stucrtures, $86 \quad 427-436 \quad$ (2008). doi:10.1016/j.compstruc.2007.02.024.

5) Z. Jian, Z. Jin-qiu, and J.I.A. Jin-feng, “Characteristic analysis of magnetorheological fluid based on different carriers,” J. Cent. South Univ. Technol., 15 252-255 (2008). doi:10.1007/s11771.

6) X. Biao, L. Yiping, and R. Hongjuan, "Review on magneto-rheological fluid and its application,” Am. J. Nanosci. Nanotechnol. 2014, 2 (4) 70-74 (2014). doi:10.11648/j.nano.20140204.12.

7) Y. Bazargan-lari, "M echanics design and shape optimization of mr brakes using nelder - mead optimization algorithm,” Mech. Ind. 20, 602 (2019). doi:doi.org/10.1051/meca/2019017.

8) J. Xu, X. Yang, W. Li, J. Zheng, Y. Wang, and M. Fan, "M echanics research on semi-active vibration isolation system based on electromagnetic spring," Mech. Ind. 21, $101 \quad$ (2020). doi:doi.org/10.1051/meca/2019048.

9) C.J. Poynor, "Modelling and testing of mr dampers," (November) 1-12 (2001). doi:10.13140/RG.2.1.2127.5604.

10) P.W. Nugroho, W. Li, H. Du, G. Alici, and J. Yang, "An adaptive neuro fuzzy hybrid control strategy for a semiactive suspension with magneto rheological damper,” Adv. Mech. Eng., 11 (2014).

11) M. Rahman, Z.C. Ong, S. Julai, M. Ferdaus, and R. Ahamed, "A review of advances in magnetorheological dampers: their design optimization and applications *," J Zhejiang Univ-Sci A (Appl Phys Eng), 18 (12) 991-1010 (2017).

12) J. Ko, N. Takata, K. Thu, and T. Miyazaki, "Dynamic modeling and validation of a carbon dioxide heat pump system dynamic modeling and validation of a carbon dioxide heat pump system," Evergreen, 7 (2) 172-194 (2020). doi:doi.org/10.5109/4055215.

13) B.F. Spencer, S.J. Dyke, M.K. Sain, and J.D. Carlson, "Phenomenological model for magnetorheological dampers,” J. Eng. Mech., 123 (3) 230-238 (1997). doi:10.1061/(ASCE)0733-9399(1997)123:3(230).

14) R. Jiménez, and L. Álvarez-Icaza, "LuGre friction model for a magnetorheological damper," Struct. Control Heal. Monit., 12 (1) 91-116 (2005). doi:10.1002/stc.58.

15) N.M. Kwok, Q.P. Ha, M.T. Nguyen, J. Li, and B. Samali, "Bouc-wen model parameter identification for a mr fluid damper using computationally efficient ga,” ISA Trans., 46 (2) 167-179 (2007). doi:10.1016/j.isatra.2006.08.005.

16) M.J.L. Boada, J.A. Calvo, B.L. Boada, and V. Díaz, "Modeling of a magnetorheological damper by recursive lazy learning," Int. J. Non. Linear. Mech., $46 \quad$ (3) 479-485 (2011). doi:10.1016/j.ijnonlinmec.2008.11.019.

17) M. Arias-Montiel, K.H. Florean-Aquino, E. Francisco-Agustin, D.M. Pinon-Lopez, R.J. SantosOrtiz, and B.A. Santiago-Marcial, "Experimental characterization of a magnetorheological damper by a polynomial model," Proc. - 2015 Int. Conf. Mechatronics, Electron. Automot. Eng. ICMEAE 2015, (November) 128-133 (2015). 
doi:10.1109/ICMEAE.2015.31.

18) G.A. Dimock, J.H. Yoo, and N.M. Wereley, “Quasisteady bingham biplastic analysis of electrorheological and magnetorheological dampers," J. Intell. Mater. Syst. Struct., 13 (9) 549-559 (2002). doi:10.1106/104538902030906.

19) J. a C. Ambrósio, M.A. Neto, and R.P. Leal, "Mechanics of materials and structures october 2007," J. Mech. Mater. Struct., 2 (October) 1515-1524 (2007). doi:dx.doi.org/10.2140/jomms.2015.10.195.

20) C.C. Chang, and P. Roschke, "Neural network modeling of a magnetorheological damper," J. Intell. Mater. Syst. Struct., 9 (9) 755-764 (1998). doi:10.1177/1045389X9800900908.

21) H. Kumar, "Optimising parameters of fused filament fabrication process to achieve optimum tensile strength using artificial neural network optimising parameters of fused filament fabrication process to achieve optimum tensile strength using artificial neural network," Evergreen, 7 (3) 373-381 (2020).

22) E.T. Maharani, U. Ubaidillah, F. Imaduddin, K.M. Wibowo, D. Utami, and S.A. Mazlan, “A mathematical modelling and experimental study of annular-radial type magnetorheological damper," Int. J. Appl. Electromagn. Mech., Preprint 1-18 (2021). doi:10.3233/JAE-201560.

23) Y. Han, L. Dong, and C. Hao, "Experimental analysis and mathematical modelling for novel magnetorheological damper design," Int. J. Appl. Electromagn. Mech., 59 367-376 (2019). doi:10.3233/JAE-171146.

24) M. Braz-César, and R. Barros, "Optimization of a fuzzy logic controller for $\mathrm{mr}$ dampers using an adaptive neuro-fuzzy procedure,” Int. J. Struct. Stab. $\begin{array}{lcc}\text { Dyn., } & \mathbf{1 7} & \text { (5) } \\ \text { doi:10.1142/S0219455417400077. }\end{array}$

25) T.G. Pratama, R. Hartanto, and N.A. Setiawan, "Machine learning algorithm for improving performance on 3 aq-screening classification," Commun. Sci. Technol., 4 (2) 44-49 (2019).

26) G.D. Nugraha, G.D. Nugraha, B. Sudiarto, and K. Ramli, "Machine learning-based energy management system for prosumer machine learning-based energy management system for prosumer," Evergreen, 7 (2) 309-313 (2020). doi:doi.org/10.5109/4055238.

27) N. Tarek, "System identification for quad-rotor parameters using neural network system identification for quad-rotor parameters using neural network," Evergreen, 3 (1) 6-11 (2016). doi:doi.org/10.5109/1657380.

28) H. Han, M. Hatta, and H. Rahman, "Smart ventilation for energy conservation in buildings smart ventilation for energy conservation in buildings," Evergreen, 6 (1) 44-51 (2019).

29) F. Imaduddin, S.A. Mazlan, Ubaidillah, M.H. Idris, and I. Bahiuddin, "Characterization and modeling of a new magnetorheological damper with meandering type valve using neuro-fuzzy,” J. King Saud Univ. Sci., $29 \quad$ (4) 468-477 (2017). doi:10.1016/j.jksus.2017.08.012.

30) M. Zeinali, S.A. Mazlan, A.Y. Abd Fatah, and H. Zamzuri, “A phenomenological dynamic model of a magnetorheological damper using a neuro-fuzzy system,” Smart Mater. Struct., 22 (12) (2013). doi:10.1088/0964-1726/22/12/125013.

31) L.H. Zong, X.L. Gong, C.Y. Guo, and S.H. Xuan, "Inverse neuro-fuzzy $\mathrm{mr}$ damper model and its application in vibration control of vehicle suspension system,” Veh. Syst. Dyn., 50 (7) 1025-1041 (2012). doi:10.1080/00423114.2011.645489.

32) H. Wang, "Modeling of magnetorheological damper using neuro-fuzzy system,” 2 1157-1164 (2009).

33) S. Materials, S.D. Nguyen, and S.B. Choi, "A new neuro-fuzzy training algorithm for identifying dynamic characteristics of smart dampers," Smart Mater. Struct., 21 (November 2014) (2012). doi:10.1088/0964-1726/21/8/085021.

34) J.-S. Roger Jang, “ANFIS : adaptive-network-based fuzzy inference system,” IEEE Trans. Syst. Man. Cybern., 23 (3) (1993).

35) F. Chang, and Y. Chang, "Adaptive neuro-fuzzy inference system for prediction of water level in reservoir," Adv. Water Resour., 29 1-10 (2006). doi:10.1016/j.advwatres.2005.04.015.

36) H. Wang, and $\mathrm{H}$. Hu, "The neuro-fuzzy identification of mr damper," 6th Int. Conf. Fuzzy Syst. Knowl. Discov. FSKD 2009, 6 (1) 464-468 (2009). doi:10.1109/FSKD.2009.545.

37) N. Talpur, M.N.M. Salleh, and K. Hussain, “An investigation of membership functions on performance of anfis for solving classification problems an investigation of membership functions on performance of anfis for solving classification problems,” IOP Conf. Ser. Mater. Sci. Eng., 226 (2017). doi:10.1088/1757-899X/226/1/012103.

38) F. Gaxiola, P. Melin, and F. Valdez, "Comparison of neural networks with different membership functions in the type-2 fuzzy weights," Adv. Intell. Syst. Comput., 322 707-713 (2015). doi:10.1007/978-3319-11313-5.

39) O.A.M. Ali, A.Y. Ali, and B.S. Sumait, “Comparison between the effects of different types of membership functions on fuzzy logic controller performance," Int. J. Emerg. Eng. Res. Technol., 3 (3) 76-83 (2015).

40) S.M. Azimi, "Designing programmable current-mode gaussian and bell-shaped membership function," Analog Integr. Circuits Signal Process., (2019). doi:10.1007/s10470-019-01567-y. 